Saudi Journal of Oral and Dental Research

Abbreviated Key Title: Saudi J Oral Dent Res

ISSN 2518-1300 (Print) |ISSN 2518-1297 (Online)

Scholars Middle East Publishers, Dubai, United Arab Emirates

Journal homepage: https://saudijournals.com

\title{
Influence of Premolar Extraction or Non-Extraction Treatment on Third Molar Eruption: A Comparative Study
}

\author{
Hammouda Dhekra ${ }^{*}$, Dallel Ines ${ }^{1}$, Ommezine Moncef $^{2}$, Tobji Samir $^{1}$, Ben Amor Adel ${ }^{1}$
}

${ }^{1}$ Orthodontic Department, Research Laboratory of oral Health and Bucco-facial Rehabilitation (LR12ES11) Faculty of Dentistry, University of Monastir, Tunisia

${ }^{2}$ Prosthodontic Department Research Laboratory of Oral Health and Bucco-facial Rehabilitation (LR12ES11) Faculty of Dentistry, University of Monastir, Tunisia

DOI: $10.36348 /$ sjodr.2021.v06i01.015 $\quad$ | Received: 28.12.2020 | Accepted: 12.01.2021 | Published: 22.01 .2021

*Corresponding author: Hammouda Dhekra

\section{Abstract}

Objective: The aim of this study was to evaluate the changes in mandibular and maxillary third molars in cases treated with and without extraction. Materials and methods: Pre-treatment (T1) and post-treatment (T2) radiographs were taken of 46 subjects who had been treated without extraction and 44 subjects who had been treated with extraction of premolars. Results: The increase of eruption space and the improvement of the angular position of third molars were statistically significant between extraction and non-extraction orthodontic treatment, whereas, there was no statistically significant difference between first premolar extraction and second premolar extraction. Conclusion: Third molar impaction for orthodontic patients can be predicted before treatment according to the size of retro molar space and the type of treatment with or without premolar extraction.

Keywords: Orthodontic treatment, malocclusion, impaction, premolar extraction, wisdom teeth.

Copyright () 2021 The Author(s): This is an open-access article distributed under the terms of the Creative Commons Attribution 4.0 International License (CC BY-NC 4.0) which permits unrestricted use, distribution, and reproduction in any medium for non-commercial use provided the original author and source are credited.

\section{INTRODUCTION}

Wisdom teeth were noted as the most frequently impacted teeth. The pattern of third molar impaction in Tunisia is characterized by a high prevalence of impaction. Of the 730 patients $50.3 \%$ showed at least one impacted third molar (ITM) [4]. Third molar impaction has been associated with several factors such as morphology, mesio-distal width, unfavorable uprighting, and path of eruption [30]. However, the main reason for third molar impaction is assumed to be a lack of retro-molar space $[3,5,6,17$, 30] Retromolar space depends in the upper jaw on the growth of the maxillary tuberosity along with alveolar growth and the mesial drift of the upper molars [8]. In the lower jaw, it depends on the resorption at the anterior border of the mandibular ramus and the direction in with the teeth erupt during the functional phase of eruption [14]. In fact, it is an extreme oral health problem; impacted or partially erupted third molars are usually associated with various pathologic conditions such as pericoronitis, dental caries, root resorptions, cystic processes, and benign or malignant tumors of odontogenic origin $[14,15]$.

Despite the presence of many investigations in this concern, predicting third molar impaction remained uncertain in orthodontics. However, it must be taken into consideration in treatment planning. The crucial point is to decide whether these will erupt or become impacted during and after orthodontic treatment, or whether they will cause secondary incisor crowding especially in the lower arch and whether extraction of some other teeth will prevent crowding and favorite eruption of third molars.

The aim of this study was to investigate the changes in mandibular and maxillary third molars in cases treated without extraction, with first and second premolar extractions.

\section{MATERIALS AND METHODS}

The present retrospective, comparative, longitudinal study was carried out in the department of orthodontics. It has reviewed 90 medical records of patients who had undergone fixed orthodontic treatment. The sample is comprised of 69 females and 21 males with mean ages 15, 8 [SD 1, 8]. There was 3 groups; non-extraction treatment was performed in 46 patients $(51,1 \%)$ and 44 patients $(48,9 \%)$ were treated with premolar extraction (23 subjects had been treated with extraction of all the fist premolar and 21 subjects had been treated with second premolar extraction). 
Exclusion criteria were as follows: patients with erupted third molar at T1, dento-facial malformation, syndrom, missing teeth or supernumery teeth.

Lateral cephalograms, panoramic radiographs, and study models of pre-treatment (T1) and of posttreatment (T2).were analyzed. All cephalograms were made with standard focus to object distance of 5 feet in order to have a real image. The following variables were noted;

On lateral cephalogram: (fig 1-2-3).

-Axial inclination of third molar: two angles were analyzed;

*The angle between the longitudinal axis of third and second molar.

*The angle between the longitudinal axis of third molar and a constructive plane, this plane was defined from Ricketts 'Xi point to the inter-incisor point.

-Retromolar maxilla space is the distance between point ptm to the distal point of the second molar.

-Retromolar mandible space is the distance between EP point and the distal point of the second molar.

-XIM: is the positional modification from $\mathrm{T} 1$ to $\mathrm{T} 2$.

(Fig 1-2)

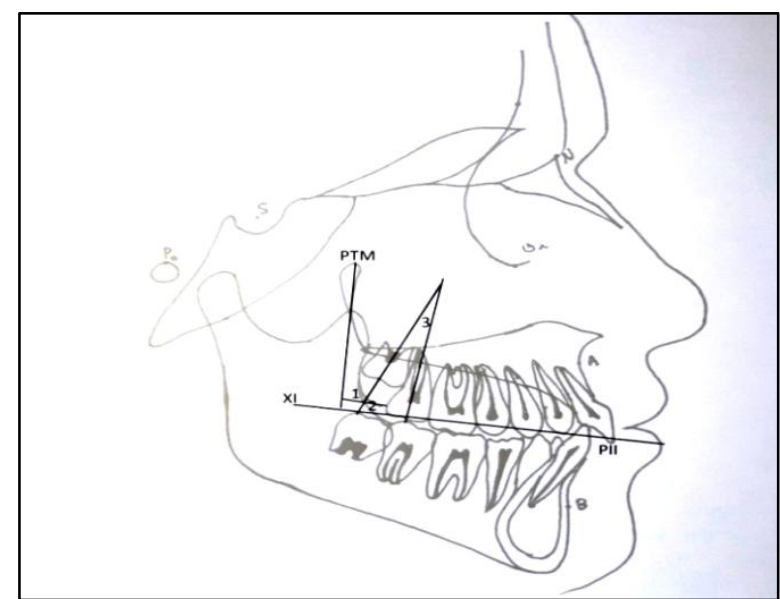

Fig-1: Measurements made on the cephalometric radiographs on the upper jaw

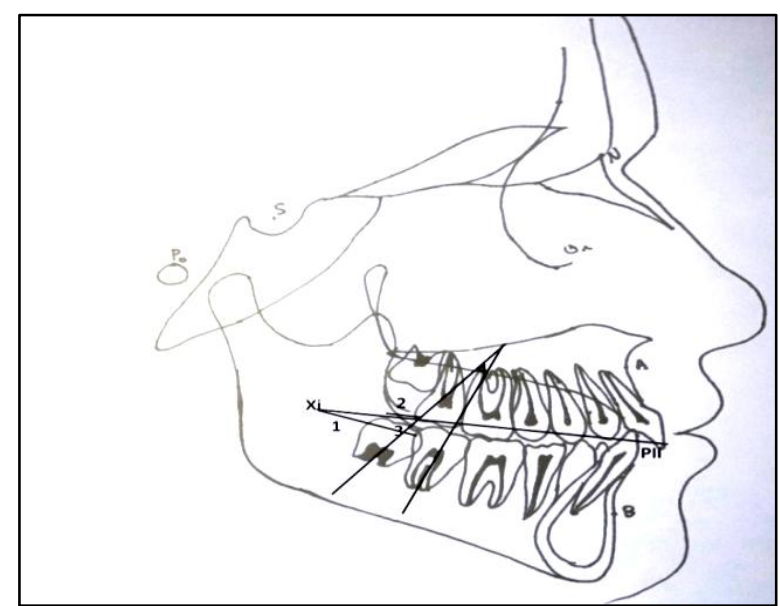

Fig-2: Measurements made on the cephalometric radiographs on the lower jaw

\section{On panoramic radiographs (fig 3);}

The outline of nasal septum was bisected and a horizontal reference plane was drawn perpendicular to the midline bisecting the nasal septum and through the outline of the hard palate.

Axial inclination of both mandible and maxilla third molar; two angles were analyzed;

* The angle between the longitudinal axis of third and second molar.

*The angle between the longitudinal axis of third molar and the horizontal reference plane.

- Retromolar maxilla space is the distance between point ptm to the distal point of the second molar.

- Retromolar mandible space was measured the distance between EP point and the distal point of the second molar.

- XIM: is the positional shift from T1 to T2 (Fig 3).

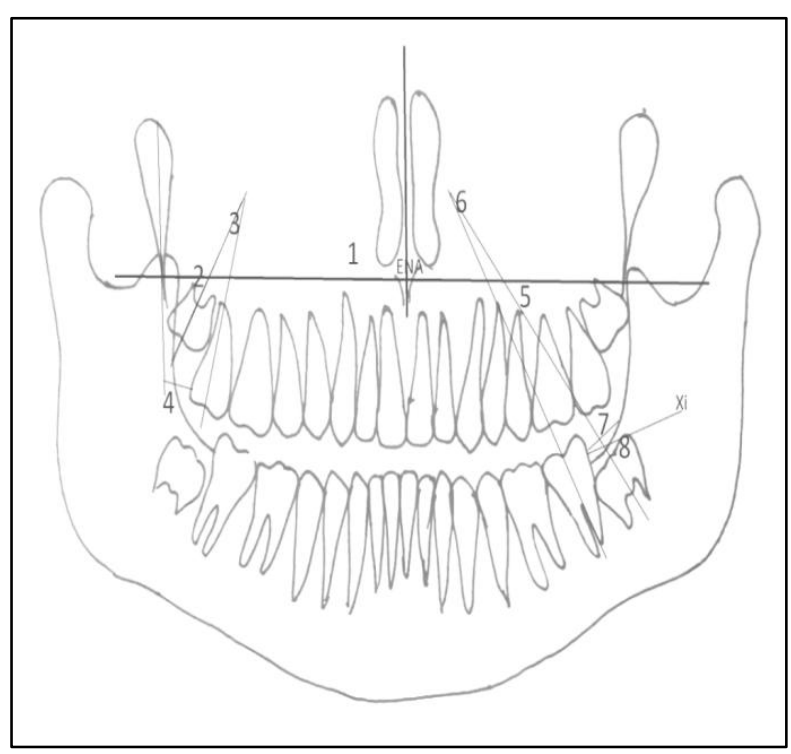

Fig-3: Measurements made on the panoramic radiographs for the upper and the lower jaw

The measurements were carried out by another examiner to determine the reliability of our examination. The data were analyzed using an SPSS program for window (version 20.0). $\mathrm{X}^{2}$ was used to compare qualitative variables. Annova test was used to compare quantitate variables.

\section{RESULT}

Comparison of extraction and non-extraction group Eruption space for third molars

In the upper jaw, the increase in PTM-M distance after treatment was significantly increased in extraction group than in non-extraction group (Table 1). 
Hammouda Dhekra et al; Saudi J Oral Dent Res, Jan, 2021; 6(1): 69-75

Table-1: Lateral cephalograms and OPG changes in the eruption space of maxillary third molars in premolar extraction and non-extraction group

\begin{tabular}{|l|l|l|l|}
\hline & Non-extraction & Extraction & p value \\
\hline Panoramic right radiographs left & 8.59 & 12.47 & 0.000 \\
& 8.89 & 12.27 & 0.000 \\
\hline Lateral cephalograms & 6.152 & 10.045 & 0.000 \\
\hline
\end{tabular}

Similarly in the lower jaw, both measurements derived from lateral and panoramic radiographs revealed a statistically significant increase in extraction group compared to non-extraction group (Table 2).

Table-2: Lateral cephalograms and OPG changes in the eruption space of mandibular third molars in premolar extraction and non-extraction group

\begin{tabular}{|l|l|l|l|l|}
\hline & & Non-extraction & Extraction & P value \\
\hline EP & Panoramic right & 11.02 & 15.65 & 0.000 \\
& Radiographs left & 10.55 & 15.68 & 0.000 \\
\cline { 2 - 5 } & Lateral cephalorams & 6.89 & 9.68 & 0.000 \\
\hline \multirow{2}{*}{ XI-M } & Panoramic right & 27.38 & 30.7 & 0.002 \\
& Radiographs left & 26.43 & 30.53 & 0.000 \\
\cline { 2 - 5 } & Lateral cephalorams & 21.21 & 24.29 & 0.001 \\
\hline
\end{tabular}

\section{Third molar orientation}

The inclination of third molars was noted on panoramic and lateral cephalograms. the angle between the longitudinal axis of third and second molar M2M3 and the angle between the longitudinal axis of third molar and the reference plane changed throughout in the upper and in the lower jaw. In one hand, in maxillary jaw, a significant decrease in M2M3 angle was noted on panoramic and lateral cephalograms Also, M3 angle showed a significant increase in extraction group compared to the other group. In the other hand, in mandible jaw, the difference in M3 and M2M3 angle was significant on lateral cephalograms. However, this change was not statistically significant for the lower jaw on panoramic radiographs (Table 3).

Table-3: Lateral cephalogram and OPG changes in the position of developing third molars in premolar extraction and non-extraction group

\begin{tabular}{|c|c|c|c|c|c|c|}
\hline & & & & Non-extraction & extraction & $\mathbf{P}$ \\
\hline \multirow[t]{6}{*}{ Maxilla } & \multirow{4}{*}{$\begin{array}{l}\text { Panoramic } \\
\text { Radiographs }\end{array}$} & M3 & $\mathrm{R}$ & 65.7391 & 75.1136 & 0.007* \\
\hline & & M3 & $\mathrm{L}$ & 67.2826 & 75.7500 & 0.002* \\
\hline & & M3M2 & $\mathrm{R}$ & 16.6739 & 10.8409 & 0.012* \\
\hline & & M3M2 & $\mathrm{L}$ & 15.8696 & 11.0227 & 0.013* \\
\hline & \multirow[t]{2}{*}{ Lateral cephalograms } & M3 & & 70.0000 & 80.5682 & $0.00 *$ \\
\hline & & M3M2 & & 13.9348 & 8.1591 & $0.04 *$ \\
\hline \multirow[t]{6}{*}{ Mandible } & \multirow{4}{*}{$\begin{array}{l}\text { Panoramic } \\
\text { Radiographs }\end{array}$} & M3 & $\mathrm{R}$ & 52.0652 & 55.5455 & 0.365 \\
\hline & & M3 & $\mathrm{L}$ & 50.7283 & 54.3409 & 0.296 \\
\hline & & M3M2 & $\mathrm{R}$ & 23.261 & 16.1250 & 0.182 \\
\hline & & M3M2 & $\mathrm{L}$ & 21.7609 & 17.0227 & 0.200 \\
\hline & \multirow[t]{2}{*}{ Lateral cephalograms } & M3 & & 56.4783 & 63.2955 & $0.05 *$ \\
\hline & & M3M2 & & 23.6957 & 15.5568 & 0.018* \\
\hline
\end{tabular}

Comparison of extraction of first premolar and extraction of second premolar group

The comparison of first and second premolar extraction treatment on lateral cephalograms revealed insignificant difference between first premolars and second premolars extraction (Table 4). 
Hammouda Dhekra et al; Saudi J Oral Dent Res, Jan, 2021; 6(1): 69-75

Table-4: Lateral cephalogram changes on retro-molar space and third molar orientation in first premolar and second premolar extraction group

\begin{tabular}{|l|l|l|l|l|l|}
\hline \multirow{2}{*}{} & & $\begin{array}{l}\text { First premolar } \\
\text { extraction }\end{array}$ & $\begin{array}{l}\text { Second premolar } \\
\text { extraction }\end{array}$ & $\begin{array}{l}\text { p } \\
\text { value }\end{array}$ \\
\hline \multirow{4}{*}{$\begin{array}{l}\text { Lateral } \\
\text { cepalograms }\end{array}$} & \multirow{2}{*}{$\begin{array}{l}\text { Retro-molar } \\
\text { space }\end{array}$} & PTM-M & 10.6 & 9.42 & 0.113 \\
\cline { 2 - 6 } & & Xi-M & 25 & 23.52 & 0.257 \\
\cline { 2 - 6 } & \multirow{3}{*}{$\begin{array}{l}\text { Third molar } \\
\text { orientation }\end{array}$} & $\mathrm{EP}$ & 9.95 & 9.3 & 0.567 \\
\cline { 2 - 6 } & $\mathrm{M} 3 \mathrm{M} 3$ & 7.91 & 12.07 & 12.17 & 0.802 \\
\cline { 2 - 6 } & $\mathrm{m} 2 \mathrm{~m} 3$ & 19.26 & 11.5 & 0.444 \\
\cline { 2 - 6 } & $\mathrm{m} 3$ & 59.21 & 67.76 & 0.108 \\
\hline
\end{tabular}

In accordance with the results from lateral cephalograms, there was no significant difference between patients treated with extraction of first and second premolars in all measurements taken on panoramic radiographs $(p>0,05)$ in the upper and the lower jaw (Table 5).

Table-5: OPG changes on retro-molar space and third molar orientation in first premolar and second premolar extraction group

\begin{tabular}{|c|c|c|c|c|c|c|}
\hline & & & & Group A & Group B & P value \\
\hline \multirow{14}{*}{$\begin{array}{l}\text { Panoramic } \\
\text { radiographs }\end{array}$} & \multirow{6}{*}{ Retro-molar space } & \multirow[t]{3}{*}{ Right side } & PTM-M & 13.28 & 11.59 & 0.110 \\
\hline & & & $\mathrm{Xi}-\mathrm{M}$ & 31.09 & 30.28 & 0.632 \\
\hline & & & Espace post & 15.99 & 15.28 & 0.551 \\
\hline & & \multirow[t]{3}{*}{ Left side } & PTM-M & 13 & 11 & 0.094 \\
\hline & & & $\mathrm{Xi}-\mathrm{M}$ & 31.76 & 30.19 & 0.066 \\
\hline & & & Espace post & 16.43 & 14.85 & 0.185 \\
\hline & \multirow{8}{*}{ Third molar orientation } & \multirow[t]{4}{*}{ Right side } & M2M3 & 10.08 & 11.066 & 0.630 \\
\hline & & & M3 & 73.73 & 76.61 & 0.501 \\
\hline & & & $\mathrm{m} 2 \mathrm{~m} 3$ & 19.32 & 12.61 & 0.207 \\
\hline & & & $\mathrm{m} 3$ & 52 & 58 & 0.228 \\
\hline & & \multirow[t]{4}{*}{ Left side } & M2M3 & 12.3 & 9.61 & 0.34 \\
\hline & & & M3 & 75.34 & 76.19 & 0.791 \\
\hline & & & $\mathrm{m} 2 \mathrm{~m} 3$ & $20 ; 86$ & 12,86 & 0.133 \\
\hline & & & $\mathrm{m} 3$ & 51,86 & 57,07 & 0.279 \\
\hline
\end{tabular}

\section{DISCUSSION}

The aim of this study was to investigate the changes in mandibular and maxillary third molars in cases treated with and without extraction. The findings of this study suggested that premolar extraction increases the chance of eruption of third molars in the lower and upper jaw. In order to identify other critical factors, we compared patients treated with first and second premolar extractions. We didn't found significant difference between first and second premolar extraction.

To attend our purpose, retro-molar space and third molar orientation were evaluated on both panoramic and lateral cephalograms taken before and after orthodontic treatment. Radiographs are an image of two dimensions (2D); this image cannot explore a three dimensional reality. Therefore, both radiographs were used in this evaluation $[1,20,22,26,29,31]$. Previous studies took either lateral cephalograms [3, 14, $27,30]$ or panoramic radiographs $[1,26,27,29,31]$ into consideration.

To compare extraction and non-extraction groups, two variables were evaluated third molar position and retromolar space. Behbahani et al. reported that measuring $\mathrm{Xi}-\mathrm{M}$ has lower method errors than measuring eruption space from the distal border of the mandibular ramus(3). Bjork [5] conducted a study using lateral cephalograms and assessed the distance from the anterior edge of the ramus to the distal surface of the second molar. This helped in evaluation of the positional change in third molars after orthodontic treatment. Axial inclination of third molar was analyzed on panoramic radiographs with a horizontal reference plane perpendicular to the midline bisecting the nasal septum and through the outline of the hard palate. This method was also used by other studies [1, 11]. However, other reference planes were used like mandibular line which was constructed as a tangent to the two lowest points on the anterior and the posterior borders of the mandibular [27, 29, 30]. An occlusal plane was also used to judge third molar angulation [14, $22,26]$. On lateral cephalograms, the reference plane was a drawn line which was from Ricketts 'Xi point to the inter-incisor point. Other studies used an occlusal plane, palatal plane and mandibular plane. Those planes could be affected by several factors such as growth and orthodontic treatment. This study was carried out on growing patients with mean age 14+/- 3 years, similar 
Hammouda Dhekra et al; Saudi J Oral Dent Res, Jan, 2021; 6(1): 69-75

to other studies $[2,3,12,14,20]$. It has been shown that retro- molar space increases $5 \mathrm{~mm}$ for each Nolla stage during M3 growth. The increase of this distance is accelerated between the age of 10 and 12 years [12]. The average age of patients included in this study 13 years, meaning that this phase was already encountered. This process, associated with the mesial displacement of the teeth, should naturally provide the M3 with enough retromolar space to allow its eruption.

\section{Comparison of extraction and non-extraction group}

The finding of this study suggested that premolar extraction in orthodontic treatment improve third molar eruption in the upper and in the lower jaw. These finding was showing by a significant increase in retro-molar space and a significant improvement in third molar orientation.

We found a significant improvement in lower third molar orientation on lateral cephalograms. However, the improvement on panoramic radiographs was not significant. We can explain that by an error while taken this radiographic. Similar results were taken by the other studies which used panoramic radiographs and palatal horizontal reference plane.

Many other articles proved that premolar extraction therapy has a positive influence in third molar development $[2,3,7,12,19,20,22,23,30]$ by increasing retro-molar space and improving third molar position. In this respect, Bjork [5] conducted a longitudinally study with orthodontic implants, he reported that patients treated with premolar extraction presented a significant increase in resorption at the anterior border of the mandibular ramus. Furthermore, some articles described a significant association between third molar impaction and non-extraction therapy [18, 24, 28]. Moreover, Salehi and al [27] included in his study a control group in order to prove that non-extraction therapy is a risk factor for impaction. In fact, evidence was sought as to the effect of appliance therapy on the final and crucial rotational movements of third molars, it was observed that $5 \%$ of the cases revealed that reverse rotations had taken place [12]. Appliance therapy that holds back molars or actively tips them distally may have the effect of encouraging abnormal rotational movement of the third molar crown and thereby increases the possibility of impaction. Haavikko et al. [16] claimed that extractions of mandibular premolars accelerated but did not favor the eruption of the mandibular third molars, he states that initial angulation of the third molars/might influence more their subsequent eruption. Bjork $[5,6]$ developed a bone remodeling theory. In this subject, Woltf [32] stated the trabeculae adapt to stress and strain formed by external forces. The third molar with appropriate initial angle may maintain the necessary external force to remodel the retromolar region by expanding the bone in all three dimensions and forming resorption of the ramal region.
Nevertheless, other authors [13, 26, 29] claimed no significant difference between extraction and non-extraction therapy and suggested that third molar angulations improves with time regardless of treatment and that other factors may influence the angulation and position of wisdom teeth.

Miclotte and al [20] investigated the effect of premolar extraction on vertical development of third molars, he revealed a significant higher upward movement of third molars after premolar extraction, his finding was in accordance with other studies [10].

The type of therapy implemented in relation to the diagnosis established is, however, an essential factor in this evolution. In the cases of TAD, the extraction space can either be totally filled by the alignment of the anterior teeth (cases of severe TAD), not allowing mesial displacement of the molars, or filled by the reciprocal movements of the distalization of the canines freeing the necessary space for the correction of the anterior crowding, and the mesial displacement of the posterior teeth.

Haavikko and al [16]. Stated that the most valuable variable was the initial angulations of third molar.when the initial angulation is less than 10 degree, the development of the eruption path is favorable; between 10 and 20 degrees the tooth is equally likely to remain at the same angle as to develop a smaller or larger angulations.

Schulhof [25] stated that third molar impaction was more likely to occur when Xi-M2 decrease below $25 \mathrm{~mm}$ and Ptm- M1 decrease below 18mm. However, the data of Kim and al [19] questioned the predictive value of $18 \mathrm{~mm}$ and $25 \mathrm{~mm}$ suggested by Schulhof. $20 \%$ of their sample experienced impaction despite a distance of $18 \mathrm{~mm}$ or more. Besides, more than $60 \%$ of the patients in their sample with less than $23 \mathrm{~mm}$ for $\mathrm{Xi}-\mathrm{M} 2$ experienced eruption of the lower third molars. Furthermore, Artun et al. [2] and Behbehani et al. [3] tried to identify risk factors for upper and lower third molar impaction by studying radiographs of orthodontic patients made before, after and at a minimum of 10 years post-retention. They reported that the decision to extract premolars in the upper jaw reduced the risk of impaction for the upper third molars by $76 \%$, whereas extractions in the lower jaw reduced the risk by $63 \%$.

In estimating the eruption space of third molar, it was recommended by some articles to use the ratio of retro-molar space to MTM width. The minimum ratio was $0.88 \%$ in erupted males and 0.9 in erupted females. In impacted group, the ratio was $1.1 \%$ and $1.09 \%$ for males and females respectively [22].

\section{Comparison of extraction of first premolar and extraction of second premolar group}

The absence of significant difference between first and second premolar extraction can be explained 
by the fact that the choice for a certain extraction pattern depends on multiple factors such as the amount of crowding, the need for incisor retraction, the underlying malocclusion and individual tooth conditions such as tooth decay, mesio-distal tooth diameter, abnormal morphology or impaction. It is reasonable that these underlying factors could play a more crucial role in the final gain in retro-molar space than the extraction pattern itself. Premolar extraction influenced third molar eruption in a way that depends on these underlying factors these factors should be taken into consideration in further studies. In accordance with those results, several studies found so significant difference $[9,20,26,29]$. However, some other studies found a significant difference, they stated that second premolar extraction has positive influence on third molars $[7,21]$.

\section{RECOMMENDATIONS}

The clinical implications of this result might favor premolar extraction in borderline extraction cases. But, this hypothesis is available in two conditions only if the third molar has a high potential of eruption and when a mesial activity of molars might provide enough space for wisdom teeth.

In severe TDM cases, premolar extraction will only provide space for anterior teeth .periodic control or germectomy might resolve this problem.

In cases with high impaction potential, severe inclination of the third molar or low retro-molar space, premolar extraction has no clear influence.

It is crucial to take wisdom teeth into consideration during orthodontic treatment plan.

\section{CONCLUSION}

The results of the present study highlight the effect of premolars extraction on third molar eruption .Our finding indicate that the extraction of either the first or the second premolar has a positive influence by increasing retro-molar space and up righting its position during active treatment.

Our finding also indicates that the premolar position's doesn't influence third molar eruption. Other factor such as initial angulation, initial retro-molar space, TDM, facial divergence, might have a stronger influence.

\section{Conflict of Interest statement}

All authors declare that we have no conflict of interest of this work.

\section{REFERENCES}

1. Al Kuwari, H. M., Talakey, A. A., Al-Sahli, R. M., \& Albadr, A. H. (2013). Influence of orthodontic treatment with first premolar extraction on the angulation of the mandibular third molar. Saudi Med J, 34(6), 639-43.

2. Årtun, J., Behbehani, F., \& Thalib, L. (2005). Prediction of maxillary third molar impaction in adolescent orthodontic patients. The Angle Orthodontist, 75(6), 904-911.

3. Behbehani, F., Artun, J., \& Thalib, L. (2006). Prediction of mandibular third-molar impaction in adolescent orthodontic patients. American journal of orthodontics and dentofacial orthopedics, 130(1), 47-55.

4. Newton, K. A. (2004). Biochemical studies on scorpion (Mesobuthus tamulus) and bee (Apis mellifera) venom peptides. Sheffield Hallam University (United Kingdom).

5. Björk, A. (1963). Variations in the growth pattern of the human mandible: longitudinal radiographic study by the implant method. Journal of dental Research, 42(1), 400-411.

6. Bjork, A., \& Jensen, E. Palling M. Mandibular growth and third molar impaction. Acta Odontol Scand 1950 .

7. Celikoglu, M., Kamak, H., Akkas, I., \& Oktay, H. (2010). Effects of orthodontic treatment and premolar extractions on the mandibular third molars. Australian Orthodontic Journal, 26(2), 160.

8. Chipman, M. R. (1961). Second and third molars: their role in orthodontic therapy. American Journal of Orthodontics, 47(7), 498-520.

9. DIERKES, D. D. (1975). An investigation of the mandibular third molars in orthodontic cases. The Angle Orthodontist, 45(3), 207-212.

10. Elsey, M. J., \& Rock, W. P. (2000). Influence of orthodontic treatment on development of third molars. British journal of oral \& maxillofacial surgery, 4(38), 350-353.

11. Feng, G. Y., Zou, B. S., Gao, X. M., Zeng, X. L., Wang, X. J., \& Yan, Y. (2013). Influence of the mandibular second premolar extraction on the angulation of the mandibular third molar. Beijing da xue xue bao. Yi xue ban= Journal of Peking University. Health sciences, 45(1), 77-80.

12. Gohilot, A., Pradhan, T., \& Keluskar, K. M. (2012). Effects of first premolar extraction on maxillary and mandibular third molar angulation after orthodontic therapy. Journal of oral biology and craniofacial research, 2(2), 97-104.

13. Graber, T. M., \& Kaineg, T. F. (1981). The mandibular third molar--its predictive status and role in lower incisor crowding. Proceedings of the Finnish Dental Society. Suomen Hammaslaakariseuran toimituksia, 77(1-3), 37.

14. Gungormus, M. (2002). Pathologic status and changes in mandibular third molar position during orthodontic treatment. J Contemp Dent Pract, 3(2), $1-9$.

15. Güven, O., Keskln, A., \& Akal, Ü. K. (2000). The incidence of cysts and tumors around impacted third molars. International journal of oral and maxillofacial surgery, 29(2), 131-135. 
Hammouda Dhekra et al; Saudi J Oral Dent Res, Jan, 2021; 6(1): 69-75

16. Haavikko, K., ALToNEN, M., \& MATTILA, K. (1978). Predicting angulational development and eruption of the lower third molar. The Angle Orthodontist, 48(1), 39-48.

17. Kandasamy, S., \& Woods, M. G. (2005). Is orthodontic treatment without premolar extractions always non- extraction treatment?. Australian dental journal, 50(3), 146-151.

18. Kaplan, R. G. (1975). Some factors related to mandibular third molar impaction. The Angle Orthodontist, 45(3), 153-158.

19. Kim, T. W., Årtun, J., Behbehani, F., \& Artese, F. (2003). Prevalence of third molar impaction in orthodontic patients treated nonextraction and with extraction of 4 premolars. American journal of orthodontics and dentofacial orthopedics, 123(2), 138-145.

20. Micolotte, A., Grommen, B., Cadenas de LlanoPérula, M., Verdonck, A., Jacobs, R., Williams, G. (2005). The effect of first and second premolar extractions on third molars; A retrospective longitudinal study. Aust Dental J, 50(3):146-51.

21. Ong, H. B., \& Woods, M. G. (2001). An occlusal and cephalometric analysis of maxillary first and second premolar extraction effects. The Angle Orthodontist, 71(2), 90-102.

22. Patel, A. K., Deshmukh, S. V., Naik, C. R., Jethe, S., \& Patel, K. A. (2015). Radiographic assessment for predicting the mandibular third molar eruption after orthodontic treatment in first premolar extraction group and non-extraction group: aretrospective study. International Journal of Dental Health Concerns, 1(1), 1-6.

23. Richardson, M. E. (1989). The effect of mandibular first premolar extraction on third molar space. The Angle Orthodontist, 59(4), 291-294.
24. Richardson, M. A. R. G. A. R. E. T. (1978). Preeruptive movements of the mandibular third molar. The Angle Orthodontist, 48(3), 187.

25. Schulhof, R. J. (1976). Third molars and orthodontic diagnosis. Journal of clinical orthodontics: JCO, 10(4), 272.

26. Russell, B., Skvara, M., Draper, E., Proffit, W. R., Philips, C., \& White Jr, R. P. (2013). The association between orthodontic treatment with removal of premolars and the angulation of developing mandibular third molars over time. The Angle Orthodontist, 83(3), 376-380.

27. Salehi, P., \& Danaie, S. M. (2008). Lower third molar eruption following orthodontic treatment. EMHJ-Eastern Mediterranean Health Journal, 14 (6), 1452-1458, 2008.

28. Silling, G. (1973). Development and eruption of the mandibule. Angle Orthod, 43:271-8.

29. Tarazona, B., Paredes, V., Llamas, J. M., Cibrián, R., \& Gandia, J. L. (2010). Influence of first and second premolar extraction or non-extraction treatments on mandibular third molar angulation and position. A comparative study. Med Oral Patol Oral Cir Bucal, 15(5), e760-e766.

30. Türköz, Ç., \& Ulusoy, Ç. (2013). Effect of premolar extraction on mandibular third molar impaction in young adults. The Angle Orthodontist, 83(4), 572-577.

31. Ventä, I. (1993). Predictive model for impaction of lower third molars. Oral surgery, oral medicine, oral pathology, 76(6), 699-703.

32. Wolff, J. (1986). The law of bon remodeling; berlin, Germany; springer-verlag. 